\title{
The SWIMS CD-ROM Pilot: Using Community Development Principles and Technologies of the Information Society to Address Identified Informational Needs
}

\author{
Daniel Teghe, Bruce Allen Knight, and Cecily Knight \\ Central Queensland University, Mackay, Australia
}

\section{d.teghe@cqu.edu.au b.knight@cqu.edu.au c.knight@cqu.edu.au}

\begin{abstract}
In this paper we describe a pilot project to develop and assess the potential of CD-ROM based resources to address the identified informational needs of a community of education professionals. We focus on the development process, although we also briefly describe the project evaluation and its results. The context in which the pilot was developed and implemented was the Social Well-being in Mackay Schools Program, in which a model was being developed to address issues of young people presenting 'at risk' within educational settings.

The development and distribution of the CD-ROM was not an easy or straightforward task, requiring extensive research and community consultation. It also required drawing on theoretical and methodological insights from across disciplines (especially from Community Development and Education) to develop a contextually relevant understanding of the factors affecting the informational needs of the community, and of the ways in which the process of addressing these needs might lead to the empowerment of its members. The ease with which the relevant technologies were accessed and used by researchers and community workers who possessed no formal or advanced training in the use of ICTs indicated that the 'new' technologies can readily complement and assist in community development, thus giving impetus to the thesis that new forms of empowerment are possible because of the advent of the Information Society.
\end{abstract}

Keywords: CD-ROM, informational needs, community development, schools, teachers, children at risk, support systems, Social Well-being in Mackay Schools, subsidiarity, power

\section{Introduction}

There is increasing evidence of the information and communication technologies (ICTs) being used to transform many of the activities that occupy people in their day-to-day lives (Harris, 1999). At the very least, the so-called 'Information Society' (which the ICTs have enabled) complements traditional ways in which people learn, and share or exchange information. The Information Society, also offers the potential for improvements to the social economy at the local

Material published as part of this journal, either on-line or in print, is copyrighted by Informing Science. Permission to make digital or paper copy of part or all of these works for personal or classroom use is granted without fee provided that the copies are not made or distributed for profit or commercial advantage AND that copies 1) bear this notice in full and 2) give the full citation on the first page. It is permissible to abstract these works so long as credit is given. To copy in all other cases or to republish or to post on a server or to redistribute to lists requires specific permission from the publisher at Publisher@InformingScience.org level, including the availability of local information, thus minimising the referred costs of certain social needs (Harris, 1999). Here, the 'Information Society' refers to the community members' information capability, and consists of a combination of information awareness, ability to access in- 
formation, and skills in exploiting information through the use of the 'new technologies' (e.g., the use of the Personal Computer and the employment of computer software applications to speedily share and distribute information) (Harris, 1999).

This paper reports on a project conducted by a team of Central Queensland University researchers which explored the efficacy of a particular approach to addressing the specific informational needs of a community of education professionals. These professionals worked in a regional Queensland state school which participated in the Social Well-being in Mackay Schools (SWIMS) program. Briefly, the SWIMS program was concerned with developing a model for service delivery to children and families presenting 'at risk' within formal educational settings. The development of the CD-ROM was part of a wider process, which included consultation and the application of community development principles, research into what constituted the informational needs of a particular community of professionals, and evaluating the impact of the resource CD-ROM.

Simply stated, the research problem consisted of how to effectively address the identified informational needs of education professionals who encountered a variety of issues stemming from children and families presenting at risk. The professionals were mainly concerned to understand the relevant formal state support systems, and to have ready access to information about the support systems and networks in their regional area. In response to these identified needs, a resource kit was collated and then stored in digital format on a CD-ROM, which was then distributed to all teachers in one of the schools participating in the SWIMS program. The perceived usefulness of the CD-ROM to address their informational needs and to build their capacity to deal with at risk issues was then evaluated through a questionnaire. The data that this questionnaire yielded revealed that the teachers found the CD-ROM to be useful, and that it addressed their informational needs and made them aware of relevant services and resources in the local community.

In the following sections we discuss the context of the project; we outline how the informational and resource needs of a group of education professionals were researched; we detail the process of (and means employed in) developing the resource CD-ROM; and, we summarise the results of the CD-ROM evaluation questionnaire. We conclude from our research that the approach developed would serve as an effective model for identifying and addressing communities' informational needs in a way that is relevant to them. However, further work is needed to refine and develop this model and identify further factors which might affect its impact when implemented in other contexts.

\section{Discussion}

\section{The Context}

In Australia, the numbers of young persons on care and protection orders and the numbers in outof-home care are on the increase. For example, over the period from June 1997 to June 2001, the numbers of children on care and protection orders increased from 15,718 to 19,783 , and the numbers of children in out-of-home care increased from 14,078 to 18,241 (Australian Institute of Health and Welfare, 2002). Costs associated with dealing with child abuse and youth crime in Australia are also increasing, with the Productivity Commission (2002) estimating that from 2000 to 2001 the increase in total government expenditure on child protection in Australia to have been 8 percent. The children are generally referred to in the relevant professional and policy circles as being 'at risk'.

An indication of what constitutes "risk" in this context is provided by the formal support and protection systems, which report that children who come into contact with them for protective reasons include those: 
- who have been or are being abused, neglected or otherwise harmed; or

- whose parents cannot provide adequate care or protection (AIHW, 2002).

However, the expression 'at risk' can, as Carroll, Baglioni, Houghton and Bramston (1999, p. 378) point out, become a 'catch all' phrase that encompasses not only children with academic difficulties, but also more specifically '...those with severe behavioural and emotional disorders who are thought likely to fail to achieve their potential development in adolescent years'. In the SWIMS program, the term 'at risk' referred to two specific dimensions of 'at risk'. The first dimension dealt with the immediate physical, emotional and social conditions for individual wellbeing, which included such stressors and harmful conditions as family and domestic violence, and emotional, sexual and physical abuse. The second dimension dealt with conditions that affected educational outcomes for individual students (Teghe, Knight \& Knight, 2003).

In the conditions of increasing rates of 'at risk' issues, there is also a common understanding that teachers are generally ill prepared to source (or coordinate the delivery of) health and human services in schools (Knight, 2000), and so more effectively address the 'at risk' issues that they might encounter. Queensland state school teachers are required to undertake a four-hour training course to familiarise themselves with child protection policies and statutes, but there is doubt whether this is sufficient training to adequately address their informational needs in respect to 'at risk' issues in educational contexts (Teghe, Knight \& Knight, 2003). Indeed, other studies indicate that even though a majority of teachers report that they sometimes find they need to help children and their families with life issues such as abuse and economic hardship, most have no training (formal or otherwise) to deal with these issues, or know where to get help, or know how to access support services in their school or community (Palmer, McCorkle, Durbin \& O'Neill, 2001). The government provider of education in state schools, Education Queensland, does employ school-based guidance officers, but these are not always available in state schools, nor are they trained to deal with some of the issues relevant to 'at risk' situations. Guidance officers tend to come from a teaching background and have postgraduate training in student counselling which draws mainly from the discipline of psychology (Teghe, Knight \& Knight, 2003).

\section{The SWIMS Program}

The Social Worker in Mackay Schools (SWIMS) program was introduced in 2002 with the aim of developing a model to address the issues described above, and which can promote collaboration and information sharing between the formal state child protection and youth justice agency and the existing systems of support for children and youth in educational settings. To develop the SWIMS program, a partnership was formed between the Mackay offices of the Queensland Department of Families (DoF) and Education Queensland (Ed Qld), and the Central Queensland University's Faculty of Education and Creative Arts. In its first year, the program employed a senior social worker, and in its second year a community worker, to "link statutory Child Protection response frameworks to interdisciplinary service provision in schools" (Project proposal, the SWIMS program) in three Mackay schools that agreed to take part in the program. In its second year, the program's name was changed to Social Well-being in Mackay Schools, and thus retained its original acronym (SWIMS).

The principal aspect in the methodology for program development used by the field workers and the researchers was the facilitation of input and participation by consumer groups in decisionmaking processes and program development. The main facilitation methods employed in the program included:

- Consultation with consumers and stakeholders at all levels of program development

- Mapping and linking existing community networks and developing new ones 
- Building the capacity of actors at all levels to deal more effectively with 'at risk' issues as they arise

- Advocacy and activism

\section{Identifying Informational Needs (Including a Methodology for Consultation)}

The research described here is not embedded in an experimental methodology because this is not useful in understanding power and its effects (Flyvbjerg, 1998, 2002; Teghe, 2001). Power, which is a contested concept (Lukes, 1974) is a central concern to program implementations that use community development principles; however, power is not quantifiable or measurable (Clegg, 1989; Dyrberg, 1997; Hindess, 1996) and the use of descriptive statistics, narratives and case studies is hence more appropriate to research into complex social problems (Flyvbjerg, 2001).

The principle of subsidiarity is central to community development. This principle dictates that power should be devolved to all members of a community - including those that are recognised as having the capacity to exercise the least influence over the decision-making processes which affect their lives (Hirst, 1994; Kenny, 1999). In other words, subsidiarity requires an approach that empowers, which, in turn, means that the capacity to make a difference (i.e., power) is devolved to all community members in a way that allows them to contribute to what they see as relevant processes and activities as is meaningful to them. The 'development' component refers to the approach as differing from the more traditional human services in that it attempts to develop '...lasting structures that help people collectively to identify and meet their own needs' (Kenny, 1999, p. 24). Although they adopted community development principles that promoted participatory action, the researchers and stakeholders in the SWIMS program were also aware that participatory development processes could be transformed into covert manipulation - a phenomenon that has been recognised and labelled as 'elegant power' (Boyd, 2000).

The principal issues identified by SWIMS participants through a series of scoping exercises as requiring urgent attention were the need for better 'communication', and for relevant education and training support. Subsequent research indicated that teachers and support staff often found themselves in situations where they wished they could do more for students and parents, but were restricted by lack of rapid access to resources and appropriate information - for instance, as when they were asked for specific information (examples given included: housing, parenting advice, information on health matters, guidance).

The principal often feels that he should've been a social worker when he has to advise parents who call him to discuss behavioural problems their children might display at home. "I'm not a social worker, parents call and want advice on other [than school] matters" (Principal - interview notes)

We don't have the capacity to fully engage the parents to direct them to programs such as 'positive parenting' or 'conflict management'. This kind of support is needed-there are agencies dealing with it, but only in bits, not as a whole (Guidance officer - meeting notes)

Professionals from outside the educational context that often and regularly liased with educationalists also made observations that further supported the existence of the informational needs identified by the school communities. For example,

Teachers need more training in how to identify and approach cases, and to understand the requirements of the [Child Protection] Act. They sometimes misunderstand their role in this respect, as exemplified by their belief that reporting is mandatory, when it is not. (DoF staff member interview notes) 


\section{Initial Strategies to Address Informational Needs}

The social worker, followed by the community worker in the second year, then began to work with the community to address its informational needs, through such actions as informational workshops, in-school exhibitions, building informational resources, and so on. Nevertheless, although these strategies were assessed as having positive outcomes in the community, the need to access information or resources on demand remained largely un-addressed. This can be partially explained by the issue of a lack of sufficient and necessary skills, knowledge and learning networks within a community when faced by development and transformation in regional socioeconomic transitional processes (Centre for Research and Learning in Regional Australia, 2002). As an example, if a parent asked a teacher for information that would help clarify or resolve a particular 'at risk' issue, the teacher in some cases did not know how to respond, and directed the parent to an administrative or support staff member (in most cases the school principal or the guidance officer). This often led to unsatisfactory outcomes for parents as they might have found it uncomfortable to speak with another person, or may have had to wait to see the person and then lost interest and left. In subsequent interviews, the SWIMS researchers found that teachers often voiced a concern that they wished they had access to locally relevant information and resources on 'at risk' issues when talking to some parents and students. Teachers did not see it as being their role to search for, and collect such information or resources, and also found they did not have the time or professional links to more effectively direct some of their students and their parents to other sources for help. For example, one needs to make an appointment to visit the guidance officer in most schools. This indicated to the researchers that particular information, or knowledge, is institutionalised and so is harder to access when actually needed, and this can reduce the sustainability of a community.

A 'sustainable geographical community' implies that people in a given place are communicating and can be informed (Harris, 1999). In keeping within community development principles, which hold that meaningful community information implies the deinstitutionalisation of knowledge (Harris, 1999; Martin, 1989), a strategy was developed within the SWIMS program to make more informational resources available to each of the teachers in the participating schools so as to empower them, whether individually or collectively, to more efficiently address 'at risk' issues. It is recognized in the literature that the challenge of participatory techniques is to rest knowledge in and with the people who will be using it (Boyd, 2000). However, one of the theoretical assumptions underpinning the approach developed within the SWIMS program was that it is possible to more easily implement participation and other and individual empowerment principles within an Information Society because of wider access to, and increasing capacities to use, new technologies.

Working on this assumption, the SWIMS research team developed and maintained a web site with online resources and a discussion forum that could be accessed by all members of the community. However, the team also had access to a large collection of print resources (brochures, leaflets, directories) that had been collected by the social worker in the first year of the SWIMS program. These could not be easily and economically uploaded to the web site because of the relatively large sizes of the electronic files generated after conversion to digital format, and the time it would have taken most people to download or even view them online. Broadband access to the Internet was not yet widely used by people in the Mackay region because of its high cost, and so a large directory of online informational resources was deemed impractical in terms of addressing the identified needs of the target community. After consultation with teachers and support staff in the schools, the SWIMS research team developed a plan to put the informational resources that they and the field workers had collected on a CD-ROM to be distributed to all individuals within the relevant community of professionals. However, a pilot study of the effectiveness of the CD-ROM was first to be undertaken in the smallest of the participating schools. 


\section{Using CD-ROMs to Provide Information Effectively: What the Lit- erature Says}

CD-ROMs have been used by educationalists for some time to deliver course material to a range of students; see, for example, O'Reilly and Morgan (1997); Macdonald, Mason and Heap (1999); Barrett and Lally (2000); and, Kim, Soonbok, Sunkyung, Eunyong and Younglan (2003). However, studies also show that, when developed and designed to promote the interactive use of the information contained on them, CD-ROMs are more effective in addressing users' informational and learning needs. For example, Ochoa (2002) describes the use of CD-ROM based interactive technology to more effectively inform teachers of guidelines to disciplining students with disabilities. In another instance, Paquin (2002) reports that those with low academic ability have positive learning outcomes when using an interactive CD-ROM. Mashinter and Kraiker (1997) present a case study of a course developed to deliver a cost effective method of informing Canadian civil aviators of new certification regulations. Smith et al (1996) outline an example of using a CD-ROM to provide a simulated emergency management experience and to create interactive educational multimedia for health workers. Messecar, Van Son and O'Meara (2003) analysed the use of CD-ROMs in self-taught statistics for nurses. See also Perdan and Azapagic (2003), and Coppieters, Parent and Piette (2003).

There are, however, few reports that describe the whole of the process (including the assessment of actual informational needs) through which a CD-ROM used to deliver information on demand to a particular community might be developed. One exception is the Building Understandings in Literacy and Teaching (BUILT) CD-ROM, which was developed for teacher education at the University of Melbourne in 2001. This video-based interactive CD-ROM was developed within a constructivist model of delivering educational programmes for situated learning, but it also owed its subsequent success (viewed as the perceptions of users collected through two evaluations of the CD-ROM) to a whole process approach that included consultation, designing/development, implementing, evaluation, evaluation, redeveloping and re-evaluation (Love and Shrimpton, 2002)

\section{The Development and Design of the SWIMS CD-ROM}

In this section we describe how the CD-ROM was developed and implemented in one of the participating schools. In the next section, we outline results of the evaluation of the SWIMS resources CD-ROM pilot.

Technology in itself does not cause learning or knowledge transmission (Brennan, McFadden \& Law, 2001). People must have the capacity to use technology to access knowledge accessible through that technology. The choice for using a resource CD-ROM as one of the means to address the informational needs of teachers in the SWIMS program was influenced by the assessment that most teachers had access to, and the capacity to use, a personal computer and a web browser. It should be noted that ownership or access to a PC, together with the ability to use one, would influence the effectiveness of a community development program that uses the CD-ROM approach to build the knowledge base of that community and its members.

Before developing the CD-ROM, the researchers were aware that, within instructional design, two major frameworks have emerged - objectivism and constructivism. In an objectivist approach, the designer sets the performance objectives and creates a systematic, but controlled, approach to delivering the information content. On the other hand, constructivism is less contentoriented and more user-centered, with the designer aiming to develop an information rich, and socially meaningful, delivery platform (Gold, 2001). The research team adopted the latter approach and, when designing the CD-ROM, the aim was to give as much control as possible to the user over their interaction with the informational resource. 'The concept of control refers to the 
freedom a user or a program has to take command of selection and sequencing of content control, display control and conscious cognition control' (Leung, 2003: 10). Following Collis and Moonen (2001), the researchers also aimed to develop an informational resource that novice users could quickly become proficient in using. Therefore, the researchers wanted to produce a CDROM that would not only contain appropriate resources and information, but that would also be easy to navigate, search, and facilitated easy and straightforward printing of resources when needed. These prerequisites meant that the navigation and functions attached to viewing and using the information to be included on the CD-ROM had to be carefully designed and tested. It also meant that a range of technical skills were required for the development and design tasks, which was contrasted by the fact that none of the research team members had formal ICT training.

However, it is common knowledge that people can not only learn content through technology, but that they can also learn about technology and develop skills to use it competently (Merriam \& Brockett, 1997). One of the SWIMS researchers had a working knowledge of HyperText Markup Language (HTML), which is used in the development of web site design. This was sufficient to enable the development of a web site, in which the large amount of printed information and resources (which were converted to digital format with the aid of an inexpensive scanner whenever an electronic copy could not be obtained from original authors) was loaded as separate web pages. Other resources were also loaded into the site, such as PDF files containing the entire Child Protection Act, Education Queensland's policies and procedures manual, links to useful online resources, and so on. Navigation to and from pages on the site was made easier through the use of frames together with a simple hierarchical menu.

One of the problems next encountered was how to make the resources on the site searchable. Research revealed that many e-book compiling software could automatically add a search facility when converting a set of files, such as those making up a web site. An inexpensive e-book making program was located (Activ E-book Compiler v4.22) and used to convert the site developed by

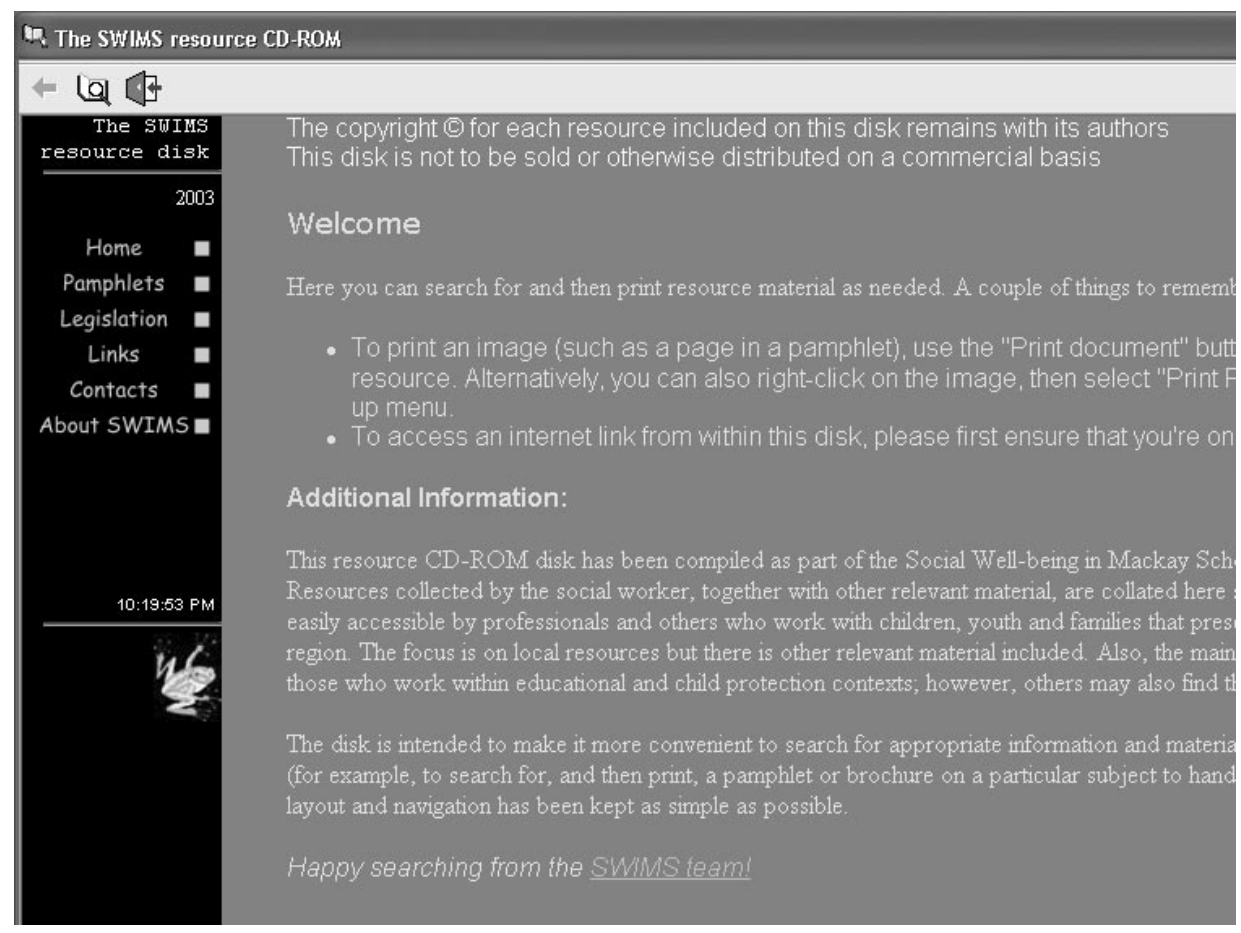

Figure 1: The index, or 'Home', page of the SWIMS resource CD-ROM showing the browser navigation, the use of frames, and the simple menu. 
the researchers into an e-book that retained the navigational facilities and characteristics of a browser (see Figure 1), but also contained a search engine that could generate meaningful results through the employment of a simple and accessible interface (see Figure 2). To facilitate the easy printing of resources from the CD-ROM, a simple Java Script was inserted with each resource, which allowed it to be printed at the 'click of a button' (see Figure 3). Lastly, to enable the easy opening of the e-book, an Autostart.inf file was added to the CD-ROM to make the e-book open automatically when the CD-ROM was inserted into the user's PC.

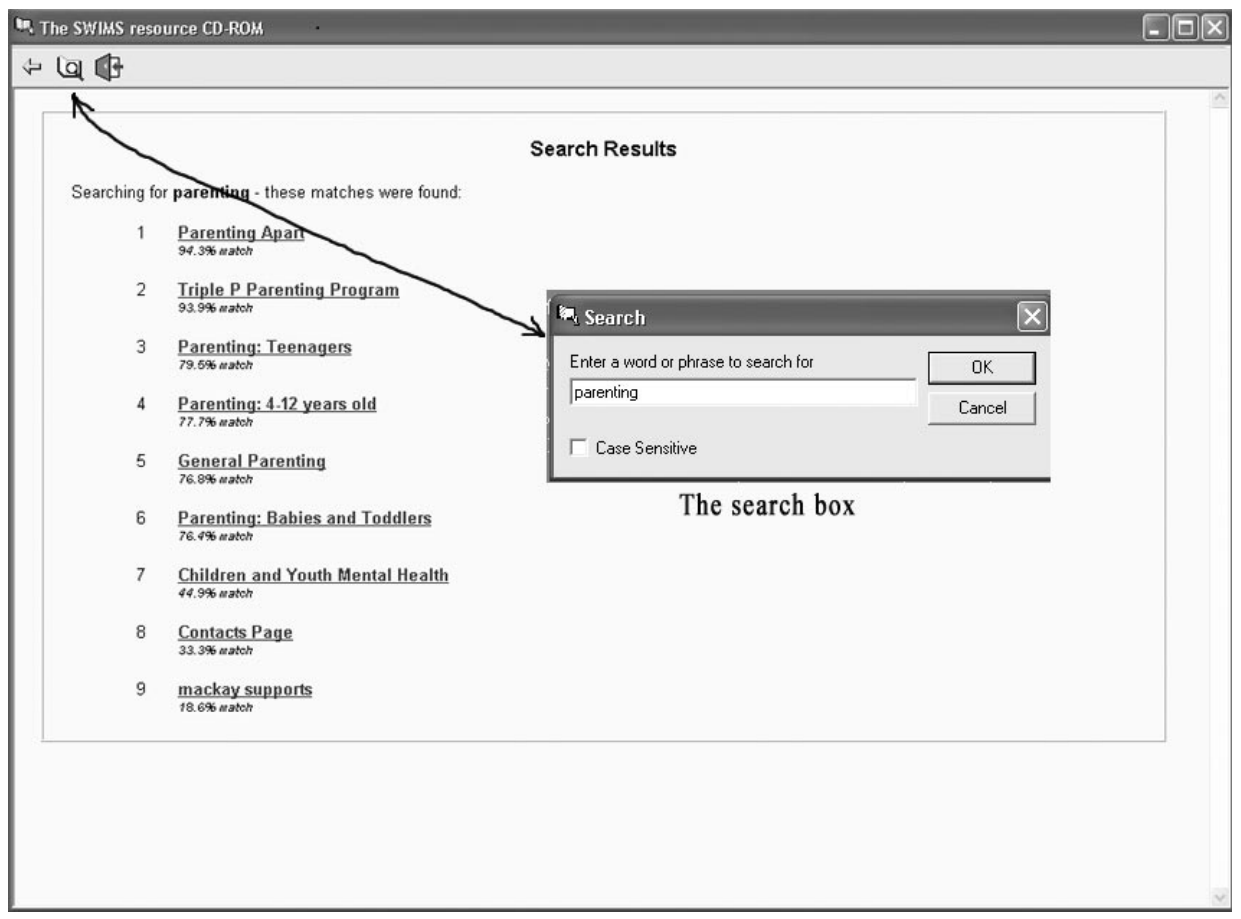

Figure 2: The search results page, showing the results as navigational links. The inset shows the search box and the keyword used to generate the results. The box can be accessed from anywhere on the CD-ROM by clicking the second of the three icons at the top of the screen. The other icons represent the 'Back' and 'Exit' functions.

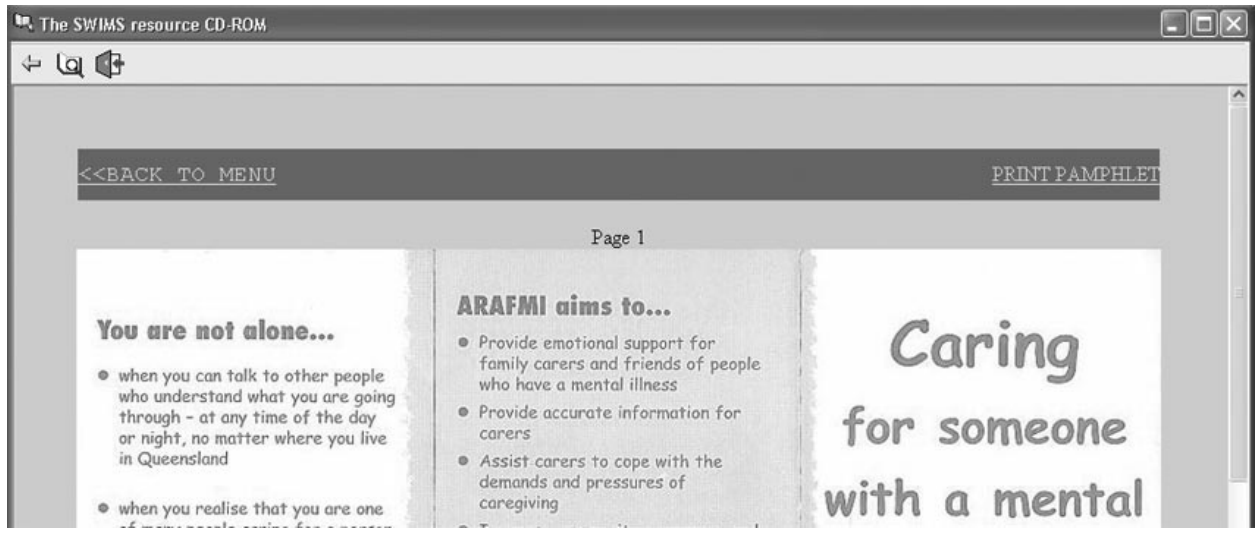

Figure 3: An individual resource page showing a pamphlet which (provided the user's PC is connected to a printer) can be printed by clicking on the 'Print Pamphlet' link shown above right of the image of the pamphlet. 


\section{Results from the Evaluation of the SWIMS CD-ROM}

The effectiveness of the SWIMS CD-ROM in addressing the informational needs of the teachers to whom the CD-ROM was distributed was assessed through the application of a short questionnaire. In designing this questionnaire, the researchers were aware that evaluation is specifically about making more or less subjective judgments on the value of data collected through observations and descriptions (Huitt, 1999). Evaluation can also become a 'verification' process, in which particular and desirable aims or outcomes are reinforced by the evaluation process itself (Power, 1999). Moreover, when the use of new technologies is required, as in the development of interactive CD-ROMs, then judgments about their effectiveness can be reduced to merely assessing the value of innovation, or the pragmatics of introducing novel techniques and resources (Harvey, Higgison \& Gunn, 2000).

The questionnaire contained two separate groups of statements, each provided with corresponding sets of response choices. The first set included five statements that referred to the functionality of the CD-ROM. Examples included: 'The disk started when I inserted it in the drive', and 'I was able to print material off the disk'. The second set of statements referred to the relevance of resources found on it by teachers. Examples of statements in this section included, 'Some of the information on the disk is relevant to my work', 'The disk raised my awareness of services available in Mackay'. The respondents could choose from a set of responses provided for each of the statements, from the 'yes/no' dichotomy, to 'perhaps', 'use occasionally', 'don't know', and so on, depending on the statements. One of the statements in the second section ('The proportion of information relevant to me in my work is close to...') was provided with percentage figures as the response choices (i.e., 0\%, 25\%, 75\%, 100\% and 'don't know'). There were ten responses from a total of seventeen teachers to which the CD-ROM was distributed, translating into almost a sixty percent response rate.

The majority of respondents thought that the quality of the CD-ROM was good, that they could easily navigate through the content and find resources and information items. Table 1 summarizes some of the results obtained from the second section of the evaluation questionnaire:

Table 1. Summaries of selected results from the SWIMS CD-ROM evaluation questionnaire

\begin{tabular}{|l|c|}
\hline Questionnaire Statement: & $\begin{array}{c}\text { Agree } \\
\text { Frequency (\%) } \\
(\mathrm{n}=10)\end{array}$ \\
\hline Information included on the disk is relevant to teachers' work & $9(90)$ \\
\hline $\begin{array}{l}\text { Can think of instance where the information and resources included } \\
\text { on the disk can be used }\end{array}$ & $9(90)$ \\
\hline Can think of instance where the use of the CD-ROM will save time & $9(90)$ \\
\hline $\begin{array}{l}\text { The disc raised individual's awareness of services that are available } \\
\text { locally }\end{array}$ & $10(100)$ \\
\hline $\begin{array}{l}\text { The disc is a good idea, and it served to build the capacity of users to } \\
\text { deal with 'at risk' issues }\end{array}$ & $9(90)$ \\
\hline
\end{tabular}

Additional statements provided by the teachers in their evaluation responses further highlighted the generally positive reception of the disk. Some examples follow:

An excellent "hands-on" resource to find health services in Mackay.

I'm pleased I have a copy to refer to ... and it has made me more aware of services available.

Good to have this sort of information on hand when required. 


\section{Conclusion}

The advent of the Information Society presents opportunities to increase the capacities of individuals and communities to better address their informational needs. However, there are two types of processes that, together, can be useful in achieving this. The first one is the process through which needs are identified. The second process develops strategies to use the technologies of the Information Society to address these needs. Both of these processes can be more effectively developed through the application of community development principles which focuses on participation and the empowerment of community members on whom these processes would impact. This requires a commitment to continuous and open consultation, and a research and evaluation approach that draws its theoretical and methodological premises from across the disciplines relevant to the community context and the issues of concern.

The case of the development and piloting of the SWIMS resource CD-ROM presented in this paper demonstrates how technologies that are easily accessed can be used together with community development principles to successfully address the informational needs of a specific community of professionals. In the event, the CD-ROM was produced and distributed by researchers that had no formal training in the use of ICTs. This proved inconsequential because the resulting information delivery system produced was, in its effect, a sophisticated and well-functioning resource that, for users, gave almost instant access to relevant information and resources. Rather, the success of the SWIMS pilot resource CD-ROM disc was due to a concern of obtaining a detailed understanding of the needs of the relevant community through participatory consultation processes which guided the application of research expertise to the set of identified informational needs and issues.

Although the SWIMS resource CD-ROM pilot study indicates the approach developed is likely to be effective in identifying and addressing the informational needs of communities of educational professionals in regional settings, the approach needs to be further tested within other communities before its efficacy as a model for addressing informational needs can be generalised as being useful in most settings. Further research is required on how variances in informational needs, social issues to be addressed, location and types of communities affect the approach described here. The discrete but meagre body of literature that describes and assesses theoretical and methodological issues in respect to how the Information Society might fruitfully advance Community Development principles, also sorely needs to be developed.

\section{References}

Australian Institute of Health and Welfare (AIHW). (2002). Child protection Australia 2000-01. AIHW cat. no. CWS 16. Canberra: AIHW (Child Welfare Series no. 29).

Barrett, E. \& Lally, V. (2000). Meeting new challenges in educational research training: The signposts for educational research CD-ROM. British Educational Research Journal, 26 (2), 271-290.

Brennan, R., McFadden, M. \& Law, E. (2001). All that glitters is not gold: Online delivery of education and training. The Australian National Training Authority and The Australian Flexible Learning Framework.

Boyd, G. (2000).Village appraisal - Is this a case of elegant power? Retrieved from http://www.caledonia.org.uk/

Carroll, A., Baglioni, A.J., Houghton, S. \& Bramston, P. (1999). At-risk and not at-risk primary school children: An examination of goal orientations and social reputation. British Journal of Educational Psychology, 69, 377-392.

Centre for Research and Learning in Regional Australia (CLRA). (2002). Broken Hill: Partnership with the community: A response to the needs of a city in decline - A case study from Learning Communities in 
Education and Training (vol.2). CRLRA Project Report 01/1. Launceston: University of Tasmania. Re trieved from http://www.CRLRA.utas.edu.au

Clegg, R.S. (1989). Frameworks of power. London: Sage Publications.

Collis, B. \& Moonen, J. (2001). Flexible learning in a digital world. London: Kogan Page.

Coppieters, P., Parent, F. \& Piette, D. (2003). Development and evaluation of the use of an interactive CDROM for students at risk of disease related to occupational hazards: The case of asthma. Promotion \& Education, 10 (2), 73.

Dyrberg, T.B. (1997). The circular structure of power: Politics, identity, community. London \& New York: Verso.

Flyvbjerg, B. (1998). Rationality and power: Democracy in practice (S. Sampson, Trans). University of Chicago Press: Chicago. (Original work published 1997)

Flyvbjerg, B. (2001). Making social science matter: Why social science fails and how it can succeed again (S. Sampson, Trans). Cambridge University Press: Cambridge. (Original work published 2001)

Gold, S. (2001). A constructivist approach to online training for online teachers. Journal of Asynchronous Learning Networks. 5 (1), 35-57.

Harris, K. (1999) The online life of communities: nurturing community activity in the Information Society. In S. Pantry (Ed.), Building community information networks. London: Library Association Publishing.

Harvey, J., Higgison, C. \& Gunn, C. (2000). Evaluation. In C. Higgison (Ed.), Online tutoring e-Book. Retrieved from http://otis.scotcit.ac.uk/onlineebook

Hindess, B. (1996) Discourses of power: From Hobbes to Foucault. Oxford: Blackwell Publishers.

Hirst, P. (1994). Associative democracy: New forms of economic and social governance. Cambridge: Polity Press.

Huitt, B. (1999). Evaluation. Valdosa University's Online Educational Psychology Resources. Retrieved from http://chiron.valdosta.edu/whuitt/col/ intro/evalu.html

Kenny, S. (1999). Developing communities for the future: Community development in Australia ( ${ }^{\text {nd }}$ ed.). Melbourne: Nelson.

Kim, J., Soonbok, C., Sunkyung, L., Eunyong, J. \& Younglan, K. (2003). An experimental study of students' self-learning of the San-Yin-Jiao pressure procedure using CD-ROM or printed materials. Journal of Nursing Education, 42 (8), 371-376.

Knight, B.A. (2000). Keynote address: New basics and productive pedagogies: A Viewpoint on implementation. Building professional learning communities conference, Mackay, January.

Leung, C.K. (2003). Providing navigational aids and online learning helps to support user control: A conceptual model on computer-based learning. Journal of Computer Information Systems, Spring, 10-17.

Love, K. \& Shrimpton, B. (2002). Can one size fit all? The case of a CD ROM in teacher education. Paper delivered at the Australian Society for Computers in Learning in Tertiary Education (ASCILITE) 2002 annual conference. Winds of change in the sea of learning: Charting the course of digital education. Auckland, 8-11 December.

Macdonald, J., Mason, R. \& Heap, N. (1999). Refining assessment for resource based learning. Assessment and Evaluation in Higher Education, 24 (3), 345-355.

Martin, W.J. (1989). Community librarianship: Changing the face of public libraries. London: Library Association Publishing.

Mashinter, G. \& Kraiker, R. (1997). Delivering courseware via a CD-ROM website. Paper presented at the Australian Society for Computers in Learning in Tertiary Education (ASCILITE) 1997 annual conference. What works and why? Perth, 7-10 December. 
Merriam, S. \& Brockett, R. (1997). The profession and practice of adult education. San Francisco: JosseyBass.

Messecar, D., Van Son, C. \& O'Meara, K. (2003). Reading statistics in nursing research: A self-study CDROM module. Journal of Nursing Education, 42 (5), 220-226.

Ochoa, T. (2002). An interactive multimedia problem-based CD-ROM for teacher preparation: IDEA-97 guidelines for disciplining students with disabilities. Journal of Special Education Technology, 17 (2), $39-45$.

O'Reilly, M. \& Morgan, C. (1997). Designing WebCDs: A low cost option to enhance learning and interaction. Paper presented at the Australian Society for Computers in Learning in Tertiary Education (ASCILITE) 1997 annual conference. What works and why? Perth, 7-10 December.

Palmer, D.J., McCorkle, L., Durbin, S.B. \& O'Neill, K. (2001). Preparation and experience of elementary teachers to work with community services for at-risk children, Education (Chula Vista), 121 (3), 554565.

Paquin, M. (2002). Effects of a museum interactive CD-ROM on knowledge and attitude of secondary school students in Ontario. International Journal of Instructional Media, 29 (1), 101-112.

Perdan, P. \& Azapagic, A. (2003). Sustainable engineering design: An interactive multimedia case study. International Journal of Sustainability in Higher Education, 4 (1), 33-43.

Power, M. (1997). The audit society: Rituals of verification. Oxford: Oxford University Press.

Productivity Commission, (2002). Report on government services 2002. Canberra: AGPS.

Smith, P.K, Fardon, M., Stoll, P., Martin, A., Lines, D. \& Forsyth, K.D. (1996). Childhood seizures CDROM. Paper presented at the Australian Society for Computers in Learning in Tertiary Education (ASCILITE) 1997 annual conference. Making new connection, Adelaide, 2-4 December.

Teghe, D. (2002) The rationality of power and the Australian CACPs program, Unpublished doctoral dissertation, Deakin University, Geelong, Australia.

Teghe, D., Knight, B.A. \& Knight, C. (2003). Linking statutory child protection / youth justice systems and schools in an Australian context: the useful role of a social worker. AARE/NZRE Joint Refereed Conference Proceedings. Auckland (November).

\section{Biographies}

Dr Daniel Teghe is a postdoctoral research fellow in the Faculty of Education and Creative Arts, Central Queensland University: Mackay, and is currently the program manager in the Social Well-being in Mackay Schools project. He has published in a number of disciplinary areas, including community and regional development, political sociology, and policy studies.

Associate Professor Bruce Knight, PhD is the Associate Dean of Research in the Faculty of Education and Creative Arts, Central Queensland University. He has an extensive research and publication record, and is an experienced researcher and teacher at both the primary and tertiary education levels. Bruce has had a major role in initiating, and participating in, a number of past and ongoing large research projects that focus on educational and 'at risk' issues in regional Australia.

Ms Cecily Knight is Sub-Dean in the Faculty of Education and Creative Arts, Central Queensland University - Mackay Campus. She is an experienced teacher and administrator in both state and Catholic schools in Queensland and New South Wales. Cecily has published in a number of areas, and has expertise in the area of Early Childhood Education, and is a member of the Education advisory committee of the Queensland Centre for the Prevention of Domestic and Family Violence. 